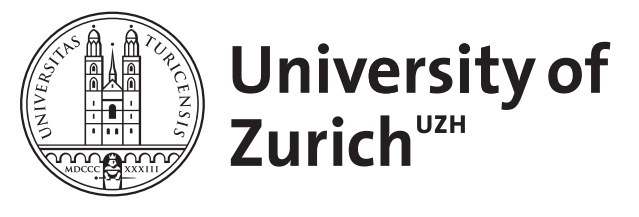

\title{
Effect of acidic solution viscosity on enamel erosion
}

\author{
Aykut-Yetkiner, A ; Wiegand, A ; Bollhalder, A ; Becker, K ; Attin, T
}

\begin{abstract}
The objective of this in vitro study was to investigate the effects of viscosity changes of different acidic solutions on dental erosion. Bovine enamel samples $(n=240, \varnothing=3 \mathrm{~mm})$ were embedded in acrylic resin and were allocated to 30 groups $(\mathrm{n}=8)$. Citric acid $(\mathrm{CA})$ and phosphoric acid $(\mathrm{PA})$ solutions at $\mathrm{pH}$ $2.5,3$, and 3.5 were prepared in de-ionized water (titratable acidity to $\mathrm{pH} 5.5: 31 \pm 0.6 \mathrm{mmol} \mathrm{OH}(-) / \mathrm{l}$ ). The kinetic viscosities of the acidic solutions were adjusted to $1.5,3,6,12$, and $24 \mathrm{~mm}(2) / \mathrm{sec}$ by the addition of hydroxypropyl cellulose (HPC) at different concentrations. Solutions were pumped over the enamel surface from a reservoir with a drop rate of $1 \mathrm{~mL} / \mathrm{min}$. Each specimen was eroded for $10 \mathrm{~min}$ at $20{ }^{\circ} \mathrm{C}$. Erosion of enamel surfaces was measured by profilometry. Data were analyzed by analyses of variance and logarithmic regression analyses $(\mathrm{p}<0.05)$. Enamel loss was dependent on viscosity, $\mathrm{pH}$, and the kind of acid. The regression analyses showed that higher viscosity caused lower enamel erosion for both acids and all pH levels. Dental erosion is dependent not only on chemical factors of the acid, like $\mathrm{pH}$ and acid type, but also on acid viscosity.
\end{abstract}

DOI: https://doi.org/10.1177/0022034512473115

Posted at the Zurich Open Repository and Archive, University of Zurich ZORA URL: https://doi.org/10.5167/uzh-86320

Journal Article

Accepted Version

Originally published at:

Aykut-Yetkiner, A; Wiegand, A; Bollhalder, A; Becker, K; Attin, T (2013). Effect of acidic solution viscosity on enamel erosion. Journal of Dental Research, 92(3):289-294.

DOI: https://doi.org/10.1177/0022034512473115 
The impact of the viscosity variations of acidic solutions on enamel erosion

Arzu AYKUT-YETKINER, Annette WIEGAND, Andrea BOLLHALDER, Klaus BECKER,

Thomas ATTIN

Arzu AYKUT YETKINER, Research Fellow, University of Zurich, Clinic for Preventive Dentistry, Periodontology and Cariology, Zurich, Switzerland, Assistant Professor, University of Ege, Faculty of Dentistry, Department of Pedodontics, Izmir, Turkey

Annette WIEGAND, Associate Professor, University of Zurich, Clinic for Preventive Dentistry, Periodontology and Cariology, Zurich, Switzerland Andrea BOLLHALDER, Dental Student, School of Dentistry, University of Zurich Klaus BECKER, University of Zurich, Clinic for Preventive Dentistry, Periodontology and Cariology, Zurich, Switzerland

Thomas ATTIN, Professor, Director, University of Zurich, Clinic for Preventive Dentistry, Periodontology and Cariology, Zurich, Switzerland word count: 195

Total word count: 2633

Total number of tables/figures: 4

Number of references: 31

Keywords: Tooth erosion, citric acid, phosphoric acid, viscosity, cellulose, $\mathrm{pH}$

Corresponding Author: Dr. Arzu Aykut Yetkiner, University of Zurich, Clinic for Preventive Dentistry, Periodontology and Cariology, Zurich, Switzerland; email, a_aykut@hotmail.com

Telephone: +4144798733743

Fax: +41446344301 


\section{ABSTRACT}

Aim: The objective of this in vitro study was to investigate the effect of viscosity changes of different acidic solutions on dental erosion. Material and methods: Bovine enamel samples $(n=240, \varnothing=3 \mathrm{~mm})$ were embedded in acrylic resin and were allocated to 30 groups $(n=8)$. Citric acid $(C A)$ and phosphoric acid (PA) solutions at $\mathrm{pH} 2.5,3$ and 3.5 were prepared in deionized water (titratable acidity to $\mathrm{pH}$ 5.5: $\left.31 \pm 0.6 \mathrm{mmol} \mathrm{OH}^{-} / \mathrm{l}\right)$. The kinetic viscosities of the acidic solutions were adjusted to $1.5,3,6,12$ and $24 \mathrm{~mm}^{2} / \mathrm{s}$ by adding hydroxypropyl cellulose (HPC) at different concentrations. Solutions were pumped over the enamel surface from a reservoir with a drop rate of $1 \mathrm{ml} / \mathrm{min}$. Each specimen was eroded for $10 \mathrm{~min}$ at $20^{\circ} \mathrm{C}$. Erosion of enamel surfaces was measured using profilometry. Data were analysed using variance analyses and logarithmic regression analyses $(p<0.05)$. Results: Enamel loss was dependent on viscosity, $\mathrm{pH}$ and kind of acid. The regression analyses showed that higher viscosity caused lower enamel erosion for both acids and all $\mathrm{pH}$ levels. Conclusion: Dental erosion is not only dependent on chemical factors of the acid, like $\mathrm{pH}$ and acid type, but also on acid viscosity. 


\section{INTRODUCTION}

Dental erosion, is defined as the pathologic, chronic, localized loss of dental hard tissues that is chemically etched away from the tooth surface by acid and/or chelation without bacterial involvement (ten Cate and Imfeld, 1996). Numerous chemical factors, like $\mathrm{pH}$, titratable acidity, degree of saturation, kind of acid and chelating properties, have been identified to influence the erosive potential of acids (West et al., 2000; Eisenburger and Addy 2003; Lussi et al., 2004; Attin et al., 2005; Lussi et al., 2012). Thereby, the frequency and duration of acid contact might determine the development and progression of erosive lesions. However, compared to the chemical factors, limited information about the effect of the physical or physico-chemical aspects of the acid on dental erosion is available yet. It is known that enamel and dentin erosion increased with increasing velocity of the acid flow, due to a faster ion exchange and clearance of dissolution products (Eisenburger and Addy 2003; Shellis et al., 2005; Wiegand et al., 2007; Attin et al., 2012). Moreover, the thermodynamic properties of acidic solutions might influence their adhesiveness to and displacement of tooth surfaces (Ireland et al., 1995), which in turn might also affect their erosive capability.

To the authors' best of knowledge, there is no information available so far about a relation between the viscosity of acidic solutions and their erosive potential. Recent studies suggest that the erosion-inhibiting effect of polymers added to acidic solutions might not only be related to the formation of an erosionprotective layer on the surface, but also to a modification of the viscosity of the drink (Hughes et al., 2002; West et al., 2004; Barbour et al., 2005). 
Therefore, the aim of this in vitro study was to investigate the effect of viscosity changes of different acidic solutions on dental erosion. The null hypothesis was that the erosivity of citric acid and phosphoric acid at different $\mathrm{pH}$-values is not affected by their viscosity.

\section{MATERIALS METHODS}

\section{Specimen preparation}

Specimens were gained from intact bovine incisors of 2-3 years old cattles. The crowns were separated from roots and stored in $0.5 \%$ thymol solution for a maximum of 6 months at $5^{\circ} \mathrm{C}$ until used. A total of 240 cylindrical enamel specimens (diameter: $3 \mathrm{~mm}$ ) were prepared using a water-cooled trephine bur and embedded in acrylic resin blocks (diameter: $6 \mathrm{~mm}$, Paladur, Heraeus Kulzer, Germany). The enamel surfaces were then ground and fine ground with water-cooled discs (1200, 2400 and 4000 grit, Water Proof Silicon carbide Paper, Struers, Erkrath, Germany). The specimens were randomly allocated to 30 groups of each $n=8$ specimens.

\section{Preparation of acidic solutions}

Citric acid (CA) and phosphoric acid (PA) solutions at $\mathrm{pH}$ levels of 2.5, 3.0 and 3.5 were used. CA solutions at $\mathrm{pH} 2.5,3.0$ and 3.5 were obtained by adding 2.81, 3.3 and $4.17 \mathrm{~g} / \mathrm{l}$ (Fluka, Buchs, Switzerland) to deionized water, respectively. PA solutions at the respective $\mathrm{pH}$-values were obtained by adding $30.5,109.3$ and $110.3 \mathrm{ml} / \mathrm{l}$, respectively from a $3 \mathrm{~mol} / \mathrm{l}$ stock solution (Merck, Darmstadt, Germany) to deionized water. In order to compare the respective acidic solutions under the same conditions, the titratable acidity (TA) of 31 
$\mathrm{mmol} \mathrm{OH}^{-} / /$to $\mathrm{pH} 5.5$ was chosen which was dictated by $\mathrm{pH} 2.5 \mathrm{CA}$ solution having a possible minimum titratable acidity of $31 \mathrm{mmol} \mathrm{OH}^{-} / \mathrm{l}$ to $\mathrm{pH} 5.5$. The titratable acidities were measured with a titrator (Metrohm, Herisau, Switzerland).

The kinetic viscosities of the acidic solutions were adjusted to $1.5,3,6,12$ and $24 \mathrm{~mm}^{2} / \mathrm{s}$, respectively by adding hydroxypropyl cellulose (HPC, Grade LM, HPC, Nippon Soda Company, Japan) at different concentrations. The viscosities were checked with a viscometer (Becker Research Equipment, Göttingen, Germany), which is described in detail in a previous study (Seeliger et al., 2010). By adding $35.8 \mathrm{~g} \mathrm{HPC}$ to a $1000 \mathrm{ml}$ of the respective acid solution, a viscosity of $34 \pm 1 \mathrm{~mm}^{2} / \mathrm{s}$ was obtained. These solutions were then diluted with the respective acid until the targeted viscosity was reached. After adjusting the viscosities the titratable acidities and the $\mathrm{pH}$ levels of the respective acidic solutions were then again measured and if necessary drops of $\mathrm{NaOH}$ or $\mathrm{HCl}$ were added for final adjustment.

The viscosities were chosen regarding the results of a preliminary test, which aimed to determine the viscosities of commercially available potentially erosive drinks. Twenty-five potentially erosive beverages marketed in Switzerland were chosen, and the viscosities of the beverages were measured 5 times for each beverage by means of the above-mentioned viscometer. The viscosities of the drinks ranged from 0.91 to $58.65 \mathrm{~mm}^{2} / \mathrm{s}$, with only few drinks exhibiting a very high viscosity ( $\geq 20 \mathrm{~mm}^{2} / \mathrm{s}$, Table 1$)$.

\section{Experimental procedure}

From each specimen five baseline profiles were recorded with a stylus 
profilometer (Perthometer S2; Mahr, Göttingen, Germany) with a distance of 50 $\mu \mathrm{m}$ between each profile. To ensure an exact repositioning of the samples during and after the experimental procedure, the profilometer and the samples were equipped with a custom-made jig (Wiegand et al., 2009).

All experiments were performed at a controlled room temperature of $20^{\circ} \mathrm{C}$. The temperatures of the respective acidic solutions were also adjusted to $20-21^{\circ} \mathrm{C}$ as the viscosity is highly depended on the temperature of a liquid (Bourne, 2002).

The respective acidic solutions were dropped from a reservoir into an inclined $\left(45^{\circ}\right)$ channel which was made from poly vinyl chloride with $8 \mathrm{~mm}$ in length of a flow rate of $1 \mathrm{ml} / \mathrm{min}$ and which directed the acidic solutions over the surface of an enamel specimen (Figure 1). The specimens were eroded for $10 \mathrm{~min}$ at a constant room temperature $\left(20^{\circ} \mathrm{C}\right)$, this means that a total amount of $10 \mathrm{ml}$ flow on each sample. Then, the specimens were rinsed with distilled water, and profilometry was performed again. Enamel wear was calculated by a custommade software (4D Client, custom designed software; University Zurich, Zurich, Switzerland), comparing the baseline profiles with the respective profiles after erosion.

\section{Data analysis}

Descriptive statistics (mean, SD) were computed, and normality of the data was checked with Kolmogorov-Smirnov and Shapiro-Wilk's tests. As normal distribution was found in all groups ( $p>0.05$ ), data were analyzed by three-way ANOVA, factors being acid type, $\mathrm{pH}$ and viscosity. As significant interactions between the experimental factors were observed, the data were split according to the acid and analyzed further by using two times two-way ANOVAs. Again 
significant interactions were found, so that the data were split according to $\mathrm{pH}$, and six times one way-ANOVA followed by Scheffé's post hoc tests was applied. Additionally a regression model was used to study the relation between viscosity and enamel erosion. The level of significance was set at $\alpha=0.05$.

\section{RESULTS}

Generally, PA caused higher erosion than CA. Mean enamel loss by erosion with CA and PA is presented in Figure 2 a-b. All one-way ANOVAs showed significant differences in enamel loss. Generally, Scheffes post-hoc tests revealed highest loss for the acid with the lowest viscosity and lowest loss for the acid with the highest viscosity (2a-b).

The logarithmic regression analysis revealed that enamel erosion decreased

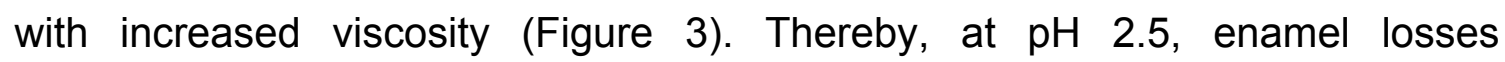
decreased from $6.8 \pm 0.6 \mu \mathrm{m}(\mathrm{CA})$ and $14.7 \pm 2.0 \mu \mathrm{m}(\mathrm{PA})$ at viscosity $1.5 \mathrm{~m}^{2} / \mathrm{s}$ to $5.0 \pm 0.5 \mu \mathrm{m}(\mathrm{CA})$ and $10.4 \pm 1.2 \mu \mathrm{m}(\mathrm{PA})$ at viscosity $24 \mathrm{~mm}^{2} / \mathrm{s}$. At pH 3, enamel losses decreased from $4.6 \pm 0.6 \mu \mathrm{m}(\mathrm{CA})$ and $7.9 \pm 1.4 \mu \mathrm{m}(\mathrm{PA})$ at viscosity $1.5 \mathrm{~mm}^{2} / \mathrm{s}$ to $2.7 \pm 0.3 \mu \mathrm{m}(\mathrm{CA})$ and $5.6 \pm 0.5 \mu \mathrm{m}(\mathrm{PA})$ at viscosity 24 $\mathrm{mm}^{2} / \mathrm{s}$. At pH 3.5, enamel losses decreased from $2.6 \pm 0.3 \mu \mathrm{m}(\mathrm{CA})$ and $2.5 \pm$ $0.5 \mu \mathrm{m}(\mathrm{PA})$ at viscosity $1.5 \mathrm{~mm}^{2} / \mathrm{s}$ to $2.0 \pm 0.3 \mu \mathrm{m}(\mathrm{CA})$ and $1.5 \pm 0.2 \mu \mathrm{m}(\mathrm{PA})$ at viscosity $24 \mathrm{~mm}^{2} / \mathrm{s}$.

\section{DISCUSSION}

To the first time it was shown that the erosive potential of acids is not only dependent on various chemical properties, such as $\mathrm{pH}$, but also on the viscosity of the acidic solution. Therefore, the null hypothesis is rejected. 
In order to isolate the effect of viscosity only, the tested acids (CA and PA) were adjusted to the same $\mathrm{pH}$-values and the same titratable acidity. Titratable acidity is an important parameter to characterize the erosive potential of different acidic solutions for the same $\mathrm{pH}$ levels. In the present study, the titratable acidity was chosen according to the native titratable acidity of citric acid at $\mathrm{pH} 2.5$. It was decided the measure the amount of base needed to raise the $\mathrm{pH}$ to 5.5 , as a $\mathrm{pH}$ equal to or less than 5.5 is traditionally considered to be critical for enamel dissolution, although mineral loss may even begin at higher pH (Birkhed, 1984). The acids and the ranges of $\mathrm{pH}$-values were chosen according to our preliminary study and the composition of typically erosive beverages (Lussi et al., 2012). The tested increments of viscosities were determined according to the results of a preliminary test, which provided us the data that viscosities of potentially erosive beverages range from 0.91 to $58.65 \mathrm{~mm}^{2} / \mathrm{s}$, with only few drinks exhibiting a very high viscosity $\geq 20 \mathrm{~mm}^{2} / \mathrm{s}$. Therefore, it was decided to use the viscosities of $1.5,3,6,12$ and $24 \mathrm{~mm}^{2} / \mathrm{s}$.

The viscosities were adjusted by adding hydroxypropyl cellulose (HPC), which is a derivative of polysaccharide cellulose and widely used in food, drug and cosmetics areas (Heitfeld et al., 2008) and is a non-ionic, water-soluble and $\mathrm{pH}$ insensitive cellulose ether (Kadajji and Betaferi, 2011).

The set up of the present study allowed for a free flow of the acid drops over the surface of the enamel specimens, so that the viscosity of the liquid rather than any pump system determined the flow rate of the acid over the surface. Due to the fact that the viscosity is directly related to the temperature of fluids (Kestin et al., 1978), not only the experiments were undertaken at a standardized 
temperature of $20^{\circ} \mathrm{C}$ but also the temperature of the tested solutions was adjusted to $20^{\circ} \mathrm{C}$.

As the erosive enamel loss decreased with increasing viscosity, it can be assumed that the relative stickiness of the acid solutions with higher viscosity decreased the ion exchange and clearance of dissolution products. The clearance of dissolution products from the enamel surface is determined by the dissolution through a static liquid layer, which becomes partly saturated with respect to mineral dissolved from the underlying enamel (Shellis et al., 2005; Wiegand et al., 2007). At higher viscosity, this static layer might be thicker and less undersaturated, so that enamel erosion decreased. However, it is not known so far if there is also any interaction between the HPC polymer and the enamel surface, which might influence the erosive potential of the HPC-modified acids. In previous studies it was shown that polymer-modified citric acid solutions with a viscosity $>50 \mathrm{mPa} s$ were less erosive than the unmodified solution under stirring conditions, probably due to the formation of a polymer layer on the surface (Beyer et al., 2010; Beyer et al., 2012). In this regard it has also to be discussed that the presence of the acquired salivary pellicle was not considered in the present study. The salivary pellicle is known to reduce erosive demineralization (Wiegand et al., 2008; Hannig et al., 2009), but might also affect the ability of liquids to adhere to enamel (Ireland et al., 1995). However, to minimize the variables in this study and to allow focusing on the viscosity, a salivary pellicle was not formed on the specimens' surface.

Xanthan gum, pectins, chitosan derivatives, dextran, carrageenan, guar gum and cellulose ethers (e.g. hydroxypropylmethyl cellulose (HPMC), hydroxypropyl cellulose (HPC), hydroxyethyl cellulose (HEC), sodium carboxy methyl cellulose 
$(\mathrm{Na}-\mathrm{CMC}))$ as well as albumin, starch or starch based derivatives are natural water soluble polymers and have been reported as inhibitors of dental erosion (West et al., 2004; Barbour et al., 2005; Hooper et al., 2007; Beyer et al., 2010; Gracia et al., 2010). Thereby, the erosion reduction mechanism was described as not only related to the formation of the gel-like polymer layer on enamel surfaces but also to an increased viscosity resulting in a reduced ion mobility and slower dissolution kinetics of polymer modified citric acid solutions (Beyer et al., 2010). The authors also hypothesized that the enamel protecting polymer layer was formed by the interactions between negatively charged carboxyl groups of polymers and calcium ions of the enamel surface and between negatively charged carboxyl groups of different polymer molecules in presence of positively charged calcium ions by forming a chelate complex (Beyer et al., 2010). HPC used in the present study is known to be non-ionic, so a binding to the surface seems relatively unlikely (see appendix).

In the present study, phosphoric acid generally caused higher enamel erosion than citric acid. This observation is in contrast to the results of previous studies, usually showing a higher erosive potential of citric acid, probably also due to the chelating properties of citric acid (Wiegand et al., 2007, Wiegand et al., 2008). It might be speculated that the free-flow mechanism of the respective acidic solutions did not provide enough time for the chelating ability of citric acid to become relevant. It must also be considered that different experimental conditions make a comparison between studies difficult, not least as the erosive potential of acids is influenced by temperature, concentration, exposure time and/or exposure type. To best of our knowledge there is no study regarding the comparison of erosive potential of $\mathrm{CA}$ and $\mathrm{PA}$ at same $\mathrm{pH}$ levels and same 
titratable acidities which might be responsible for greater erosion for PA. It has also to be considered that bovine instead of human enamel was used in this study. In this regard it has to be mentioned that bovine enamel presents a higher susceptibility to erosion than human enamel (Attin et al. 2007), probably due to differences in morphological, chemical and physical properties. Although the differences between the two substrates must be considered when interpreting results obtained from any experiment using bovine tooth substrate (Yassen et al., 2011), the use of bovine specimens seems to be appropriate when relative rather than absolute differences are of interest (Wiegand and Attin, 2011).

Although the chemical factors ( $\mathrm{pH}$ and kind of acid) had a higher influence on erosion than the physical aspect (viscosity), the present study demonstrated that modeling of erosive conditions is very complex and not only dependent on chemical aspects, like $\mathrm{pH}$ or titratable acidity, which are usually considered as erosion-determining factors.

Further studies have to show whether adding HPC to commonly consumed acidic beverages might influence their erosive potential.

Acknowledgements

The authors thank DKSH Switzerland Ltd. for providing the hydroxypropyl cellulose powders. The authors declare no potential conflicts of interest with respect to the authorship and/or publication of this article. 


\section{REFERENCES}

Attin T, Becker K, Wiegand A, Tauböck TT, Wegehaupt FJ (2012). Impact of laminar flow velocity of different acids on enamel calcium loss. Clin Oral Investig [E-pub ahead of print Apr 25, 2012] In press.

Attin T, Wegehaupt F, Gries D, Wiegand A (2007). The potential of deciduous and permanent bovine enamel as substitute for deciduous and permanent human enamel: Erosion-abrasion experiments. J Dent 35:773-7.

Attin T, Weiss K, Becker K, Buchalla W, Wiegand A (2005). Impact of modified acidic soft drinks on enamel erosion. Oral Dis 11:7-12.

Barbour ME, Parker DM, Allen GC, Jandt KD (2005). Human enamel erosion in constant composition citric acid solutions as a function of degree of saturation with respect to hydroxyapatite. J Oral Rehabil 32:16-21.

Barbour ME, Shellis RP, Parker DM, Allen GC, Addy M (2005). An investigation of some food-approved polymers as agents to inhibit hydroxyapatite dissolution. Eur J Oral Sci 113:457-461.

Beyer M, Reichert J, Heurich E, Jandt KD, Sigusch BW (2010). Pectin, alginate and gum arabic polymers reduce citric acid erosion effects on human enamel. Dent Mater 26:831-839.

Beyer M, Reichert J, Sigusch BW, Watts DC, Jandt KD (2012). Morphology and structure of polymer layers protecting dental enamel against erosion. Dent Mater [E-pub ahead of print Aug 7, 2012] In press.

Birkhed D (1984). Sugar content, acidity and effect on plaque $\mathrm{pH}$ of fruit juices, fruit drinks, carbonated beverages and sports drinks. Caries Res 18:120-127 Bourne M (2002). Food texture and viscosity: Concept and measurement. San Diego: Academic Press. 
Eisenburger M, Addy M (2003). Influence of liquid temperature and flow rate on enamel erosion and surface softening. J Oral Rehabil 30:1076-1080.

Gracia LH, Brown A, Rees GD, Fowler CE (2010). Studies on a novel combination polymer system: in vitro erosion prevention and promotion of fluoride uptake in human enamel. J Dent 38(Suppl 3):S4-11.

Hannig C, Berndt D, Hoth-Hannig W, Hannig M (2009). The effect of acidic beverages on the ultrastructure of the acquired pellicle--an in situ study. Arch Oral Biol 54:518-526.

Heitfeld KA, Guo T, Yang G, Schaefer DW (2008). Temperature responsive hydroxypropyl cellulose for encapsulation. Mater Sci Eng C 28:374-379.

Hooper S, Hughes J, Parker D, Finke M, Newcombe RG, Addy M, et al. (2007). A clinical study in situ to assess the effect of a food approved polymer on the erosion potential of drinks. J Dent 35:541-546.

Hughes JA, Jandt KD, Baker N, Parker D, Newcombe RG, Eisenberger M, et al. (2002). Further modification to soft drinks to minimise erosion - a study in situ. Caries Res 36:70-74.

Ireland AJ, McGuinness N, Sherriff M (1995). An investigation into the ability of soft drinks to adhere to enamel. Caries Res 29:470-476.

Kadajji VG, Betageri GV (2011). Water Soluble Polymers for Pharmaceutical Applications. Polymers 3:1972-2009.

Kestin J, Sokolov M, Wakeham WA (1978). Viscosity of liquid water in the range $8^{\circ} \mathrm{C}$ to $150{ }^{\circ} \mathrm{C}$. J Phys Chem Ref Data 7:941-948.

Lussi A, Jaeggi T, Zero D (2004). The role of diet in the aetiology of dental erosion. Caries Res 38(Suppl 1):34-44.

Lussi A, Megert B, Shellis RP, Wang X (2012). Analysis of the erosive effect of 
different dietary substances and medications. Br J Nutr 107:252-262.

Seeliger E, Becker K, Ladwig M, Wronski T, Persson PB, Flemming B (2010). Up to 50 -fold increase in urine viscosity with iso-osmolar contrast media in the rat. Radiology 256:406-414.

Shellis RP, Finke M, Eisenburger M, Parker DM, Addy M (2005). Relationship between enamel erosion and liquid flow rate. Eur J Oral Sci 113:232-238.

ten Cate JM, Imfeld T: Dental erosion, summary (1996). Eur J Oral Sci 241-244.

West NX, Hughes JA, Addy M (2000). Erosion of dentine and enamel in vitro by dietary acids: the effect of temperature, acid character, concentration and exposure time. J Oral Rehabil 27:875-880.

West NX, Hughes JA, Parker D, Weaver LJ, Moohan M, De'Ath J, et al. (2004). Modification of soft drinks with xanthan gum to minimise erosion: a study in situ. Br Dent J 196:478-481.

Wiegand A, Attin T (2011). Design of erosion/abrasion studies--insights and rational concepts. Caries Res 45(Suppl 1):53-59.

Wiegand A, Bliggenstorfer S, Magalhaes AC, Sener B, Attin T (2008). Impact of the in situ formed salivary pellicle on enamel and dentine erosion induced by different acids. Acta Odontol Scand 66:225-230.

Wiegand A, Stock A, Attin R, Werner C, Attin T (2007). Impact of the acid flow rate on dentin erosion. J Dent 35:21-27.

Wiegand A, Waldheim E, Sener B, Magalhães AC, Attin T (2009). Comparison of the effects of TiF4 and NaF solutions at $\mathrm{pH} 1.2$ and 3.5 on enamel erosion in vitro. Caries Res 43:269-277.

Yassen GH, Platt JA, Hara AT (2011). Bovine teeth as substitute for human teeth in dental research: a review of literature. J Oral Sci 53:273-82. 


\section{Figure Legends}

Figure 1. Flow incline allowing for rinsing 8 specimens in parallel. a: Plastic tubes attached to the pump (Internal diameter: $3 \mathrm{~mm}$ ) b: Acid drops c: Inclined U-form channel (Depth: $0.68 \mathrm{~mm}$, Width: $2.00 \mathrm{~mm}$ d: Enamel sample

Figure 2a. Enamel loss ( $\mu \mathrm{m}$, mean \pm standard deviation) caused by $\mathrm{CA}$ at $\mathrm{pH}$ 2.5, 3.0 and 3.5 and different viscosities ranging from 1.5 to $24 \mathrm{~mm}^{2} / \mathrm{s}$. Within each $\mathrm{pH}$, significant differences between the viscosities were marked by different letters.

Figure 2b. Enamel loss ( $\mu \mathrm{m}$, mean \pm standard deviation) caused by $\mathrm{PA}$ at $\mathrm{pH}$ 2.5, 3.0 and 3.5 and different viscosities ranging from 1.5 to $24 \mathrm{~mm}^{2} / \mathrm{s}$. Within each $\mathrm{pH}$, significant differences between the viscosities were marked by different letters.

Figure 3. Logarithmic regressions of viscosity of $\mathrm{CA}$ and $\mathrm{PA}$ at $\mathrm{pH}$ levels of 2.5 , 3.0 and 3.5. (R Sq Linear $=0.579,0.480,0.338$ for $\mathrm{CA} \mathrm{pH} \mathrm{2.5,} 3.0$ and 3.5, respectively; $\mathrm{R} \mathrm{Sq}$ Linear $=0.689,0.596,0.263$ for $\mathrm{PA} \mathrm{pH} \mathrm{2.5,} 3.0$ and 3.5, respectively) 


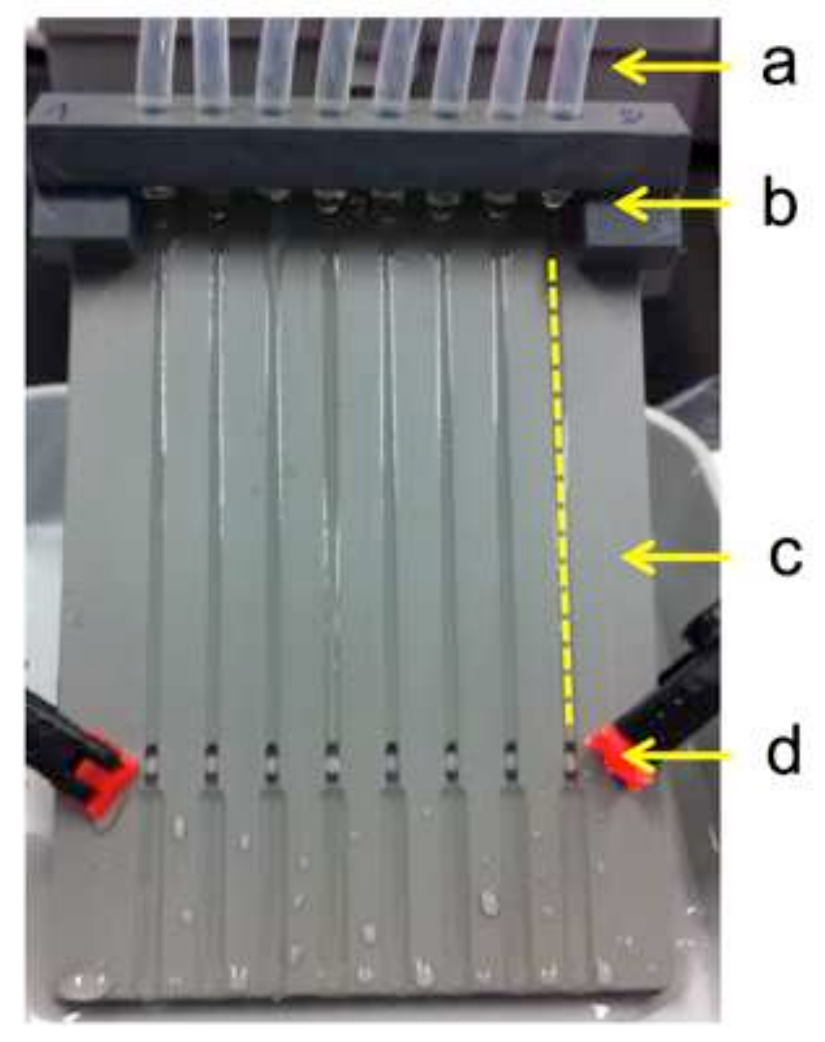

Figure 1. Flow incline allowing for rinsing 8 specimens in parallel. a: Plastic tubes attached to the pump (Internal diameter: $3 \mathrm{~mm}$ ) b: Acid drops c: Inclined U-form channel (Depth: $0.68 \mathrm{~mm}$, Width: $2.00 \mathrm{~mm}$ d: Enamel sample 


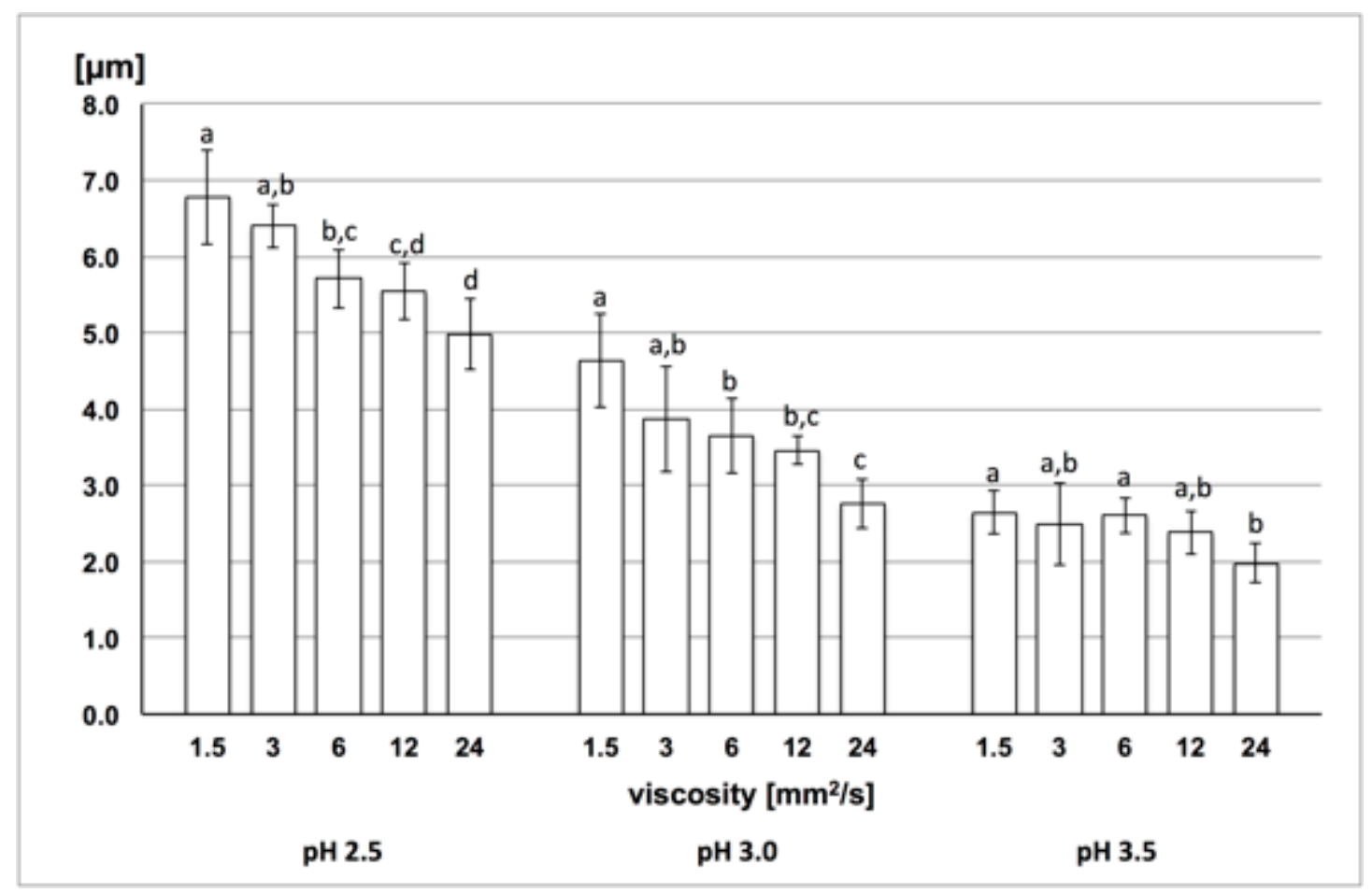

Figure 2a. Enamel loss ( $\mu \mathrm{m}$, mean \pm standard deviation) caused by $\mathrm{CA}$ at $\mathrm{pH}$ 2.5, 3.0 and 3.5 and different viscosities ranging from 1.5 to $24 \mathrm{~mm}^{2} / \mathrm{s}$. Within each $\mathrm{pH}$, significant differences between the viscosities were marked by different letters. 


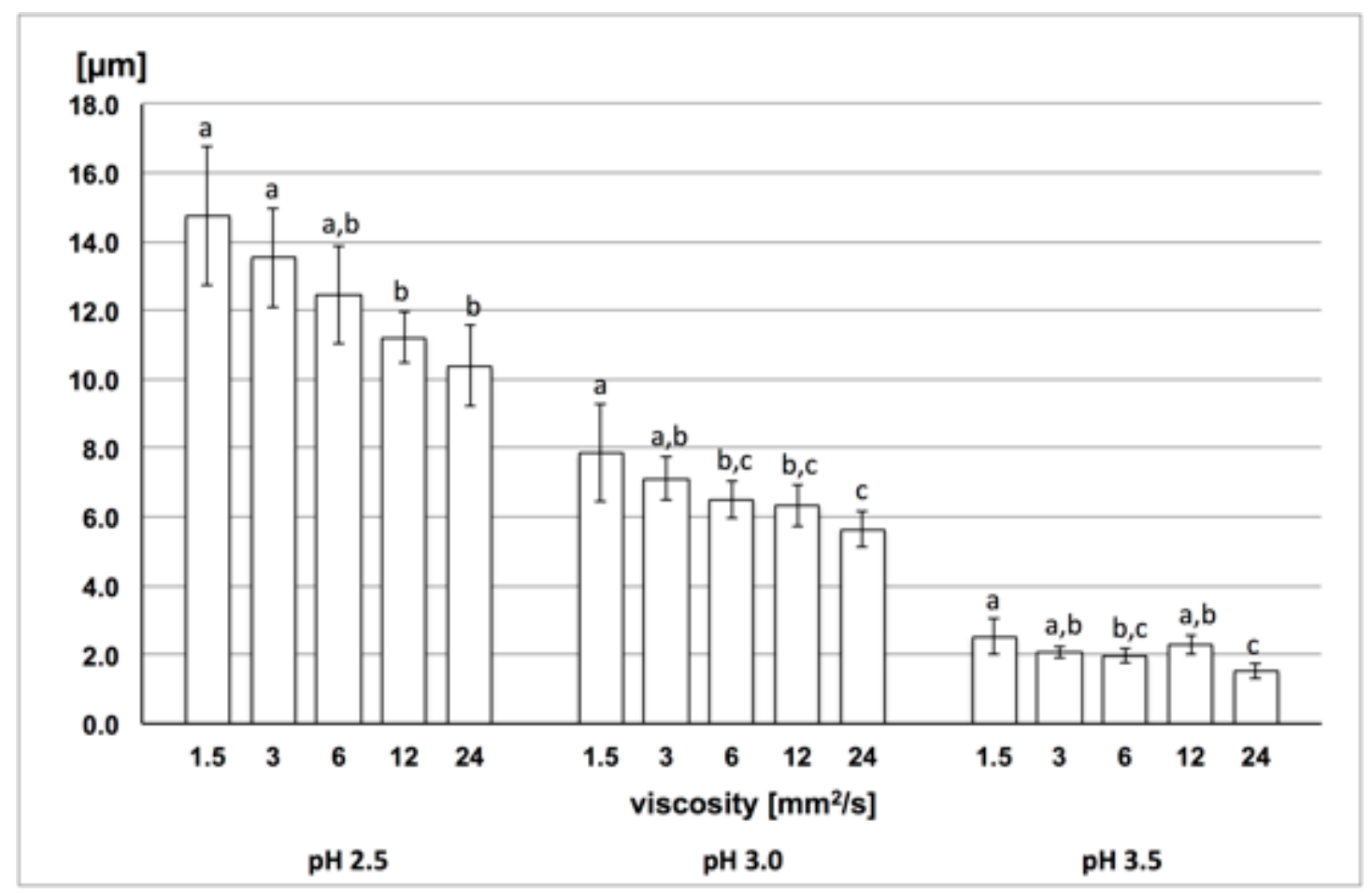

Figure $\mathbf{2 b}$. Enamel loss ( $\mu \mathrm{m}$, mean \pm standard deviation) caused by $\mathrm{PA}$ at $\mathrm{pH}$ 2.5, 3.0 and 3.5 and different viscosities ranging from 1.5 to $24 \mathrm{~mm}^{2} / \mathrm{s}$. Within each $\mathrm{pH}$, significant differences between the viscosities were marked by different letters. 


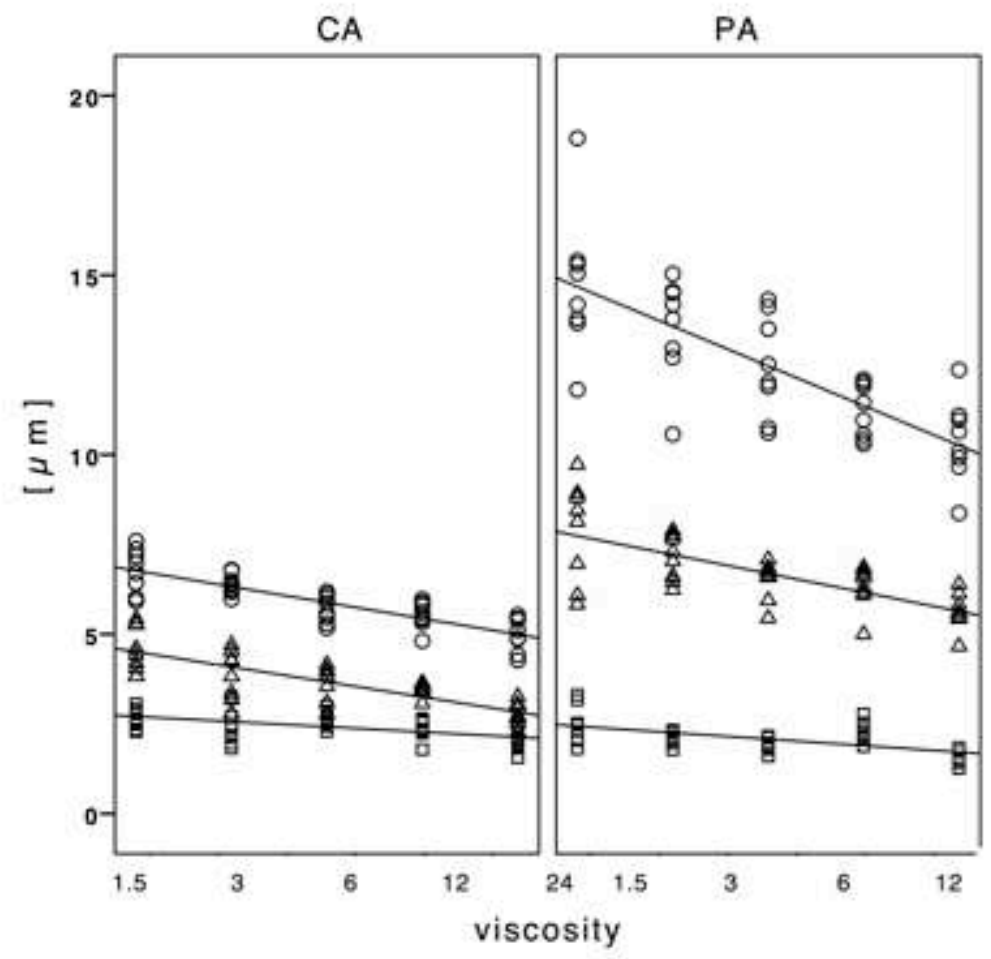

$\mathrm{pH}$

○ 2,50

$\triangle 3,00$

ㅁ 3,50

Figure 3. Logarithmic regressions of viscosity of $\mathrm{CA}$ and $\mathrm{PA}$ at $\mathrm{pH}$ levels of 2.5,

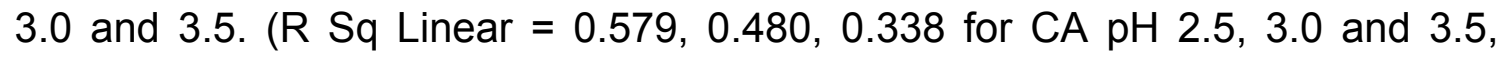

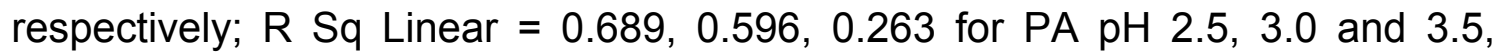
respectively) 
The impact of the viscosity variations of acidic solutions on enamel erosion

\section{APPENDIX}

\section{INTRODUCTION}

In previous studies it was shown that polymer-modified citric acid solutions were less erosive than the unmodified solution, probably due to the formation of a polymer layer on the surface (Beyer et al., 2010; Beyer et al., 2012). The authors hypothesized that a protecting polymer layer was formed by interactions between the polymers and the enamel surface (Beyer et al., 2010). To ensure that the reduction of enamel erosion by acidic solutions with higher viscosities was related to a decreased ion exchange and clearance of dissolution products rather than to a protection of enamel dissolution by any interaction between HPC and the enamel surface, the following additional experiment was performed. This experiment intended to analyse whether the pretreatment of enamel with HPC-containing acid solutions reduced further erosion by hydrochloric acid at $\mathrm{pH} 2.6$ due to any kind of mechanical protection of the enamel crystals.

\section{MATERIALS and METHODS}

Cylindrical enamel discs $(n=92)$ were embedded in acrylic resin, and enamel surfaces were ground flat with water-cooled carborundum discs (1200, 2400 and 4000 grit, Water Proof Silicon carbide Paper, Struers, Erkrath, Germany). 


\section{Calcium analysis}

Eighty-four specimens were randomly allocated to 14 groups $(n=6)$. They were pre-treated by immersion in citric or phosphoric acid $(\mathrm{pH} 2.5,3$ or 3.5) or water with or without addition of HPC (viscosity: $24 \mathrm{~mm}^{2} / \mathrm{s}$ obtained in the same way as in the present study) for $3 \mathrm{~min}$.

Following each pre-treatment, the specimens were rinsed with deionized water for 30 seconds. Then, the specimens were fixed in a superfusion chamber and were eroded for 2 minutes $\mathrm{HCl}$ acid $(\mathrm{pH} \mathrm{2.6)}$ at $60 \mu \mathrm{l} / \mathrm{min}$. The set-up was published in a previous study (Wiegand et al., 2008). Enamel loss was determined in every $15 \mathrm{~s}$ fraction by colorimetric analysis of calcium release.

The data were analysed with two-way ANOVA separately for both acids.

\section{SEM}

To further analyze any possible effect of the polymer itself on enamel erosion, SEM analysis was performed of enamel surfaces. Eight of the enamel specimens were eroded with citric and phosphoric acid or with the respective solutions with a viscosity of $24 \mathrm{~mm}^{2} / \mathrm{s}(\mathrm{pH} 3.0$, each $\mathrm{n}=2)$.

Before treatment with the test solutions, one half of the enamel surface was covered with PVC tape (Scotch, 3M, Germany) to obtain an untreated area (UT) which was protected against solution exposure. Then, the specimens were eroded for $10 \mathrm{~min}$ with the same construction used in the main study. After rinsing with distilled water for $30 \mathrm{~s}$ the tape was removed and the specimens were desiccated for 2 weeks in blue silica gel in a vacuum evaporator. 
The specimens were the mounted on aluminum stubs and sputter-coated with gold, and examined using a Supra 50 VP Scanning Electron Microscope (Carl Zeiss NTS, Oberkochen, Germany) with an acceleration voltage of $2 \mathrm{kV}$.

\section{RESULTS}

\section{Calcium analysis}

Calcium loss of enamel specimens pretreated with water with or without the addition of HPC amounted to $4.40 \pm 0.41$ and $4.36 \pm 0.26 \mathrm{mmol} / \mathrm{l}$, thus, was not different. The statistical analysis revealed that neither the $\mathrm{pH}$ nor the presence of HPC in the acid pre-treatment influenced further erosive calcium loss significantly (Appendix Figure 1 and 2).

\section{SEM}

The SEM images (Appendix Figure 3 and 4) revealed no differences between the surfaces eroded with HPC-containing acid and the surfaces, which were pretreated with the respective acid without HPC. No layer or precipitation was detected on the surfaces, indicating that no chemical binding between the polymer and enamel took place. This observation is especially true, when comparing these pictures with SEM images in a previous study (Beyer et al., 2010), which had presented distinctly visible adsorption of polymers (other than HPC) on enamel surfaces on SEM images. 
Summarizing these results, it seems unlikely that calcium release and enamel dissolution, respectively, is significantly blocked by a chemical binding of HPC to the enamel surface. 


\section{APPENDIX REFERENCE}

Beyer M, Reichert J, Heurich E, Jandt KD, Sigusch BW (2010). Pectin, alginate and gum arabic polymers reduce citric acid erosion effects on human enamel. Dent Mater 26:831-839.

Beyer M, Reichert J, Sigusch BW, Watts DC, Jandt KD (2012). Morphology and structure of polymer layers protecting dental enamel against erosion. Dent Mater [E-pub ahead of print Aug 7, 2012] In press.

Wiegand A, Meier W, Sutter E, Magalhães AC, Becker K, Roos M, Attin T (2008). Protective effect of different tetrafluorides on erosion of pellicle-free and pelliclecovered enamel and dentine. Caries Res 42:247-54. 


\section{Appendix Figure Legends}

Appendix Figure 1. Calcium loss (mmol/l, mean \pm standard deviation) in enamel samples eroded with hydrochloric acid after the immersion in the respective citric acidic solutions with or without the addition of HPC.

Appendix Figure 2. Calcium loss (mmol/l, mean \pm standard deviation) in enamel samples eroded with hydrochloric acid after the immersion in the respective phosphoric acidic solutions with or without the addition of HPC.

Appendix Figure 3. SEM images of enamel surfaces treated (10 min, $\mathrm{pH} 3.0$ ) with CA (top) or HPC-containing CA (viscosity $24 \mathrm{~mm} 2 / \mathrm{s}$, bottom) with 2000x, 10000x and 50000x magnifications. UT: untreated area.

Appendix Figure 4. SEM images of enamel surfaces treated (10 min, $\mathrm{pH} 3.0$ ) with PA (top) o- HPC containing PA (viscosity $24 \mathrm{~mm}^{2} / \mathrm{s}$, bottom) with 2000x, 10000x and 50000x magnifications. UT: untreated area. 


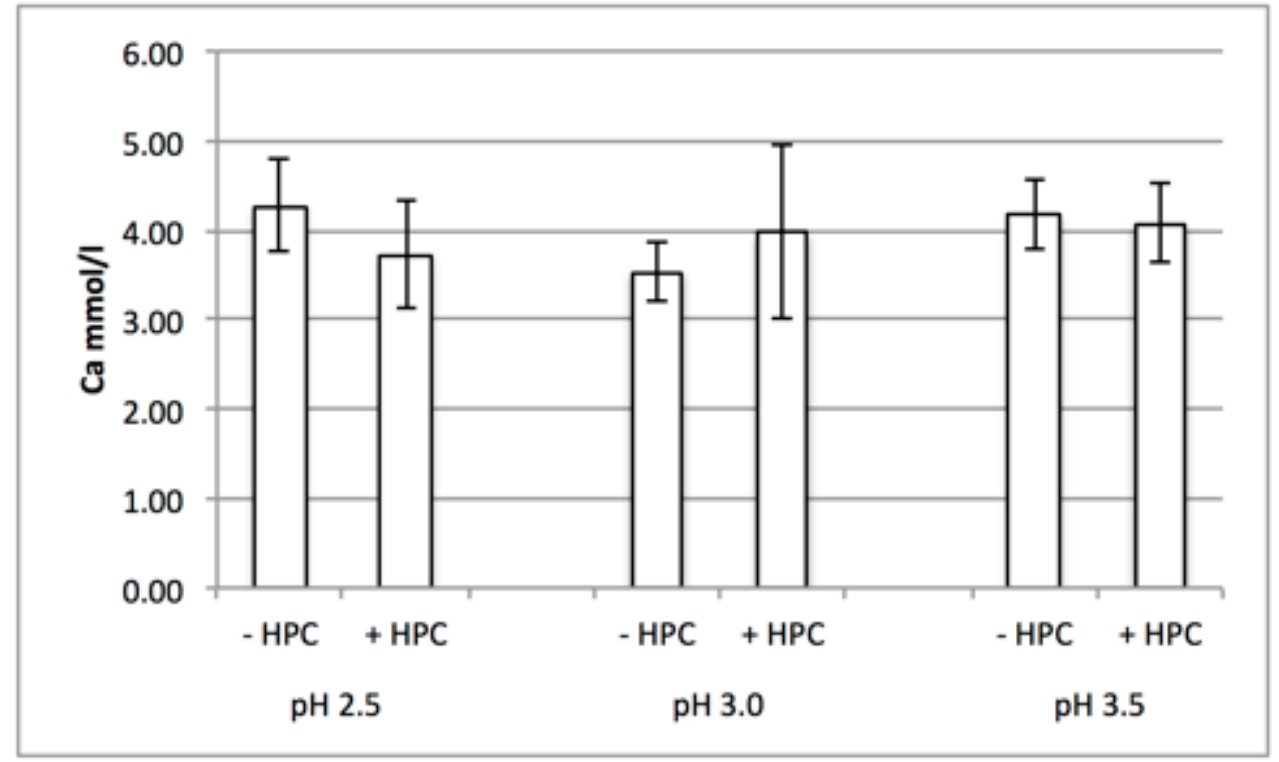

Appendix Figure 1. Calcium loss (mmol/l, mean \pm standard deviation) in enamel samples eroded with hydrochloric acid after the immersion in the respective citric acidic solutions with or without the addition of HPC. 


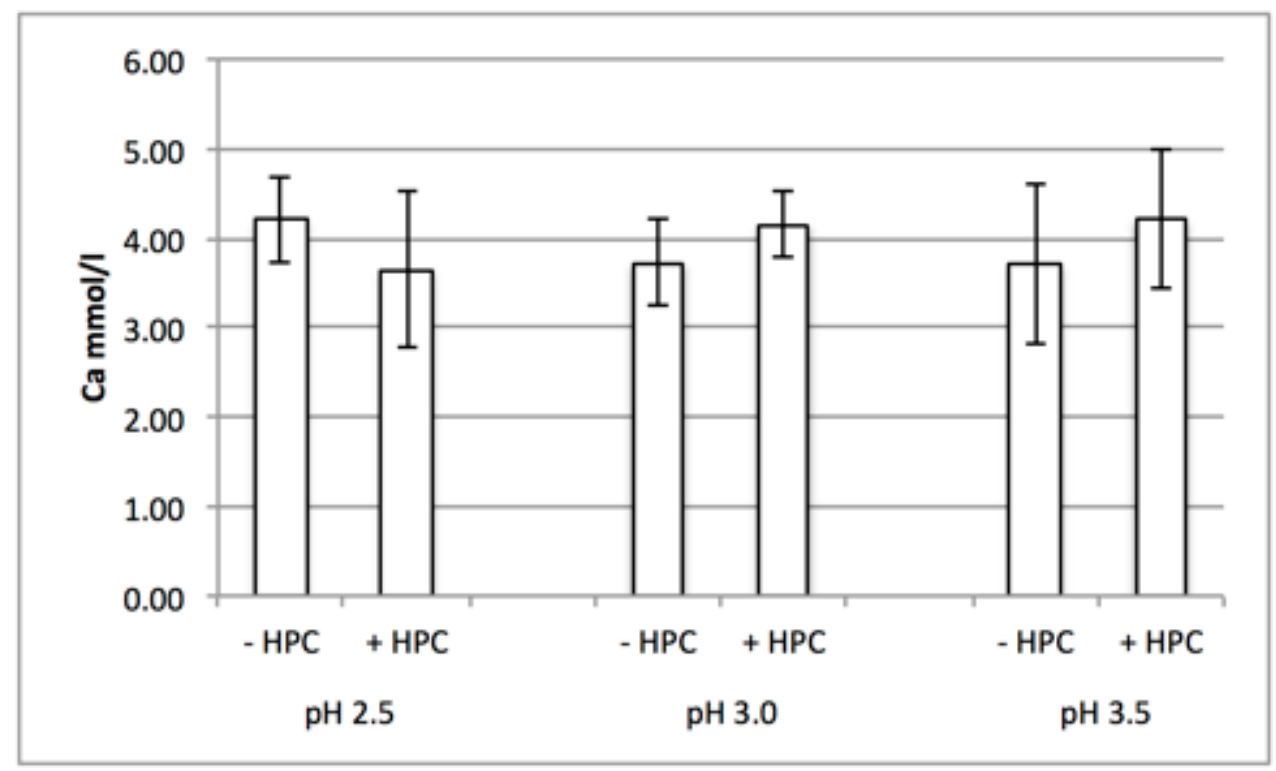

Appendix Figure 2. Calcium loss (mmol/l, mean \pm standard deviation) in enamel samples eroded with hydrochloric acid after the immersion in the respective phosphoric acidic solutions with or without the addition of HPC. 


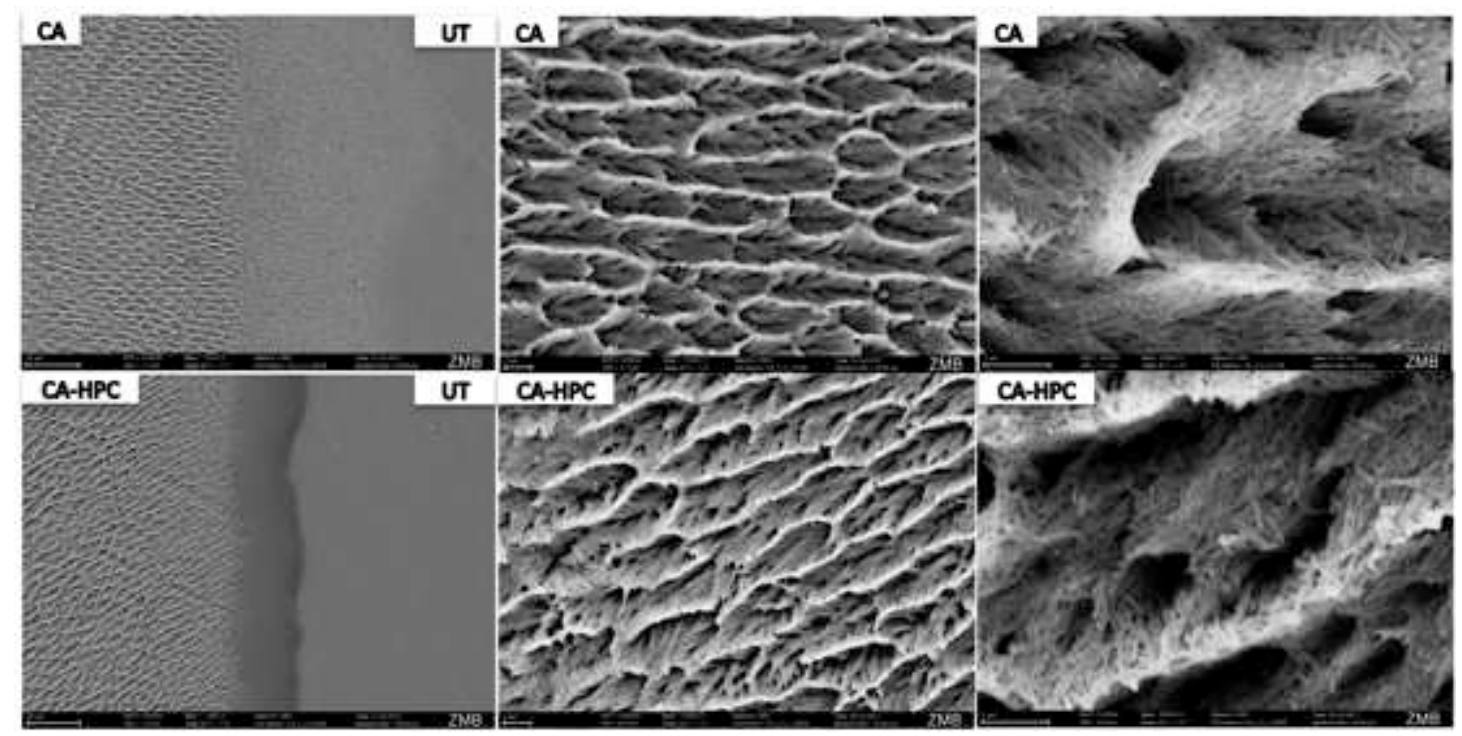

Appendix Figure 3. SEM images of enamel surfaces treated (10 min, $\mathrm{pH} 3.0$ ) with CA (top) or HPC-containing CA (viscosity $24 \mathrm{~mm} 2 / \mathrm{s}$, bottom) with 2000x, 10000x and 50000x magnifications. UT: untreated area. 


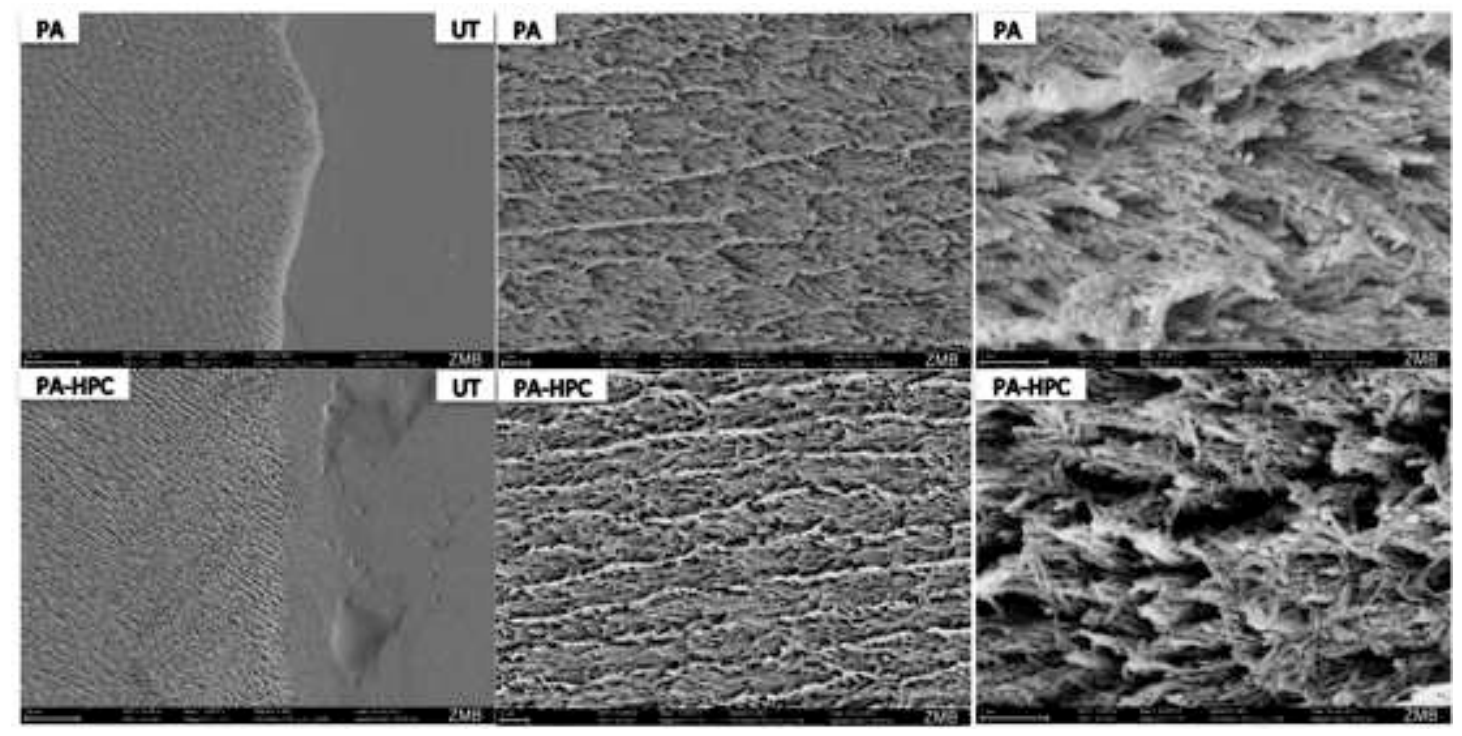

Appendix Figure 4. SEM images of enamel surfaces treated (10 min, $\mathrm{pH} 3.0)$ with PA (top) o- HPC containing PA (viscosity $24 \mathrm{~mm}^{2} / \mathrm{s}$, bottom) with $2000 \mathrm{x}$, 10000x and 50000x magnifications. UT: untreated area. 